\title{
El método crítico-estilístico como estrategia de análisis del video musical Hello again (The Cars)
}

\author{
José Ignacio Aguaded Gómez, Jennifer Rodríguez López \\ (Universidad de Huelva, España)
}

Recibido: 5/2/2012

Aprobado: 24/2/2012

\begin{abstract}
Resumen: Este artículo presenta brevemente el modelo metodológico críticoestilístico para el análisis del video musical, basándose para ello en el ejemplo práctico del video musical Hello again, de The Cars, producido por Andy Warhol en 1984. Este videoclip servirá de excusa para evidenciar las virtudes y defectos del método propuesto como herramienta didáctica y educativa, así como mostrar su eficacia como instrumento de análisis de un género audiovisual que carece en la actualidad de un método específico para su estudio de forma detallada y global.
\end{abstract}

Palabras clave: Método / análisis / video musical / Andy Warhol

The critical-stylistic method as music video analysis strategy: Hello again (The Cars)

Summary: This paper briefly presents the critical-stylistic methodology model for the analysis of the music video, drawing upon the practical example of the music video Hello again (The Cars) produced by Andy Warhol in 1984. This video will serve as an excuse to demonstrate the strengths and weaknesses of the proposed method as a teaching and educational tool, and it will show its effectiveness as an instrument for analyzing an audiovisual format that currently lacks a specific method for its detailed and global study.

Keywords: Method / analyse / music video / Andy Warhol 


\section{Introducción al método crítico- estilístico para el análisis del video musical}

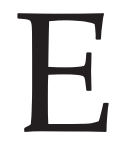

1 método utilizado para la realización del análisis del video musical Hello again de The Cars es una plantilla analítica que se caracteriza por la consecución de tres etapas: segmentación, análisis e interpretación. Estas etapas se encuentran jerarquizadas y en relación con el concepto de estilo, entendiendo este término, de forma general, como conjunto de rasgos que distinguen la personalidad de un autor en su obra.

Las etapas del ejercicio analítico de los videos musicales han sido adaptadas a partir de las similitudes entre los distintos autores que han realizado estudios sobre metodología de análisis en los ámbitos cinematográfico y publicitario. Asimismo, el modelo extraído está principalmente basado en las obras de Casetti y Di Chio (1991) y Bordwell y Thompson (1995) por su carácter sintético y su profundidad de análisis de las partes en las que quedan divididos los distintos procesos analíticos. Estos estudios han sido complementados con diferentes investigaciones y aportaciones desde la perspectiva cinematográfica y publicitaria entre los que destacan, en el análisis del filme: Zunzunegui (1989), Aumont y Marie (1990) y Carmona (2000); y en el análisis del spot publicitario: González Requena y Ortiz de Zárate (1995), Aguaded y Pérez (1995), Martí y Vallhonrat (2000), Correa,
Guzmán y Aguaded (2000) y PérezGauli (2000).

Tras el cotejo de todas las propuestas metodógicas anteriormente mencionadas, e insertas todas ellas en el campo del audiovisual, se procedió al diseño de la plantilla de análisis descrita en este artículo. Se distinguen tres etapas: la primera etapa se define por la segmentación del video musical en unidades significativas, que atendiendo a la naturaleza musical de este formato audiovisual se realiza a partir de la estructura de la canción pop que actúa como base sobre el componente visual del videoclip. Tras esta tarea, se inicia el análisis propiamente dicho a través de tres niveles en los que se estudian, en un primer nivel, las características formales del video musical, teniendo en cuenta aspectos como la composición de los planos, la iconografía, los códigos gráficos y sonoros, entre otros. El siguiente nivel alude al análisis de la representación, con el estudio de la puesta en escena y del tiempo y el espacio videográficos. Por último, se describen los rasgos relativos a la narración, entre los que se encuentran los existentes y los acontecimientos. Con la finalización de la etapa analítica se inicia la última etapa, definida por la tarea de interpretación, una fase de carácter subjetivo en la que el investigador tiene la tarea de recomponer las unidades en las que quedó segmentado el video musical tras la primera etapa pero dotándolas al hacerlo de un nuevo sentido en el 
que las partes forman un todo unitario y orgánico, y en la que se expondrán datos ajenos al video musical y en relación, por ejemplo, con su contexto de producción.

A continuación, el análisis del video musical Hello again servirá como ejemplo práctico de la metodología propuesta, en el que se evidenciarán todas las etapas y subetapas en detalle y de forma pormenorizada. La división en fases de este método permite una comparación eficaz de estas entre distintos videos musicales, por lo que se convierte en una herramienta educativa eficiente.

\section{Análisis de Hello again (The Cars)}

\section{Ficha técnica}

- Año: 1984

- Dirección: Don Munroe

- Producción: Vincent Fremont

- Producción ejecutiva: Andy Warhol T.V. Productions para The Cars
- Formato: Video, color/blanco y negro, sonido

- Duración: 6 minutos y 16 segundos

\section{Segmentación. Estructura y letra de la canción}

Intro musical. Este video musical fue realizado sobre la base de la versión extendida de la canción, tomando un sampler del single de The Cars, Heartbeat City, que aparece como primera intro para continuar después con la intro de la canción Hello again.

Hello, hello again

Hello, hello again

Estrofa I

You might have forgot the journey ends You tied your knots and you made your friends

You left the scene without a trace

One hand on the ground, one hand in space

Oh you passed on mercy

you tried the rest you gave your body you gave your best

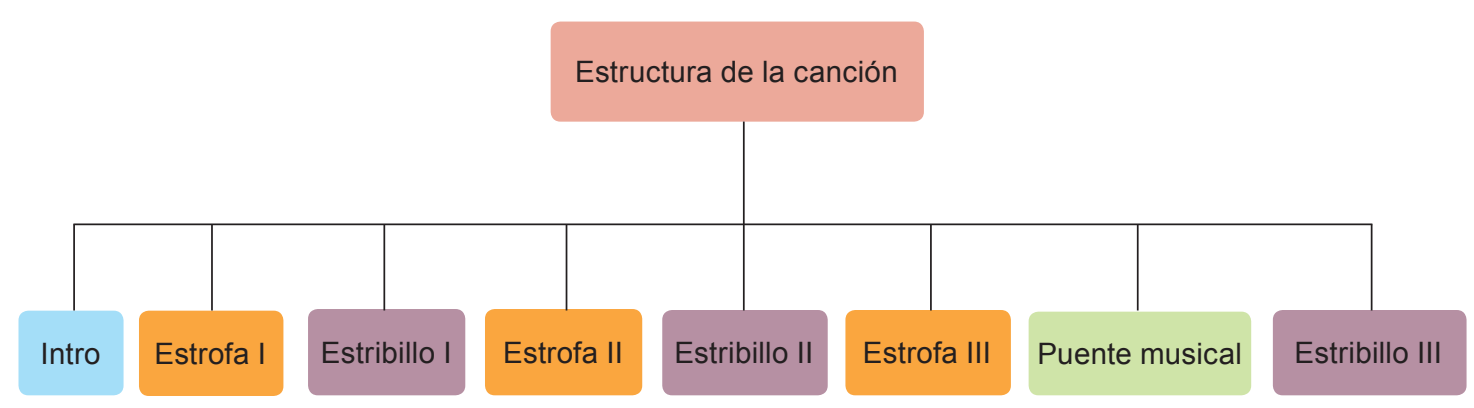


stare at the green door, livin' in the sky You don't wanna know it, you just want to fly

Estribillo I

(Hello) hello (hello again) (hello) hello (hello again)

hello, that's right

Estrofa II

I know (you're a dreamer) who's under the gun I know (you're a dreamer) who's only just begun

Estribillo II

Hello (hello) (hello again)

I say (hello) hello (hello again)

Estrofa III

Oh when there's nothin'

Nothin' left to lose

You leave it all,

To fade to blue

Puente musical

(You want to feel) electric,

(You want to feel) loose,

(You want to be) eclectic,

You want to call a truce

(Look, look) at the profile,

staring at the flame,

(Wait, wait) for the sunshine,

standing in the rain

Estribillo III

(Hello) (hello again)

I said hello (hello) hello

(hello again) hello again

I say hello (hello) hello

(hello again) hello again

(hello) (hello again)

(hello) (hello)

I said hello (hello) (hello)

\section{Análisis videográfico}

\section{Análisis formal}

\section{Códigos visuales}

- Composición fotográfica

Intros: 00:00 - 02:16

Primera intro: Sampler Heartbeat city: 00:00 - 01:18

- Plano general de un bar compuesto por piezas de tocador $y$ cuyo barman tiene como cabeza una televisión. Encuadre en escorzo e inclinación normal. La escena se completa con elementos que aparecen desde el margen izquierdo del encuadre. Color.

- Letras "The Cars" sobre el fondo de la escena anterior. Se desplazan desde el margen derecho hasta el margen izquierdo del encuadre. Blanco y negro.

- Plano-secuencia en el que la cámara sigue el recorrido de un zapato-coche por una ciudad irreal compuesta por chicas gigantes. Inclinación normal. Color.

- Plano general del cantante junto a las piernas de una de las mujeres gigantes. Encuadre frontal e inclinación normal. Color.

- Plano de media figura de la mujer gigante mientras introduce al cantante en su bolso. Color. 
- Plano general del bar del inicio en el que aparece el cantante desde el margen superior del encuadre. Encuadre frontal e inclinación normal. Color.

- Plano medio del barman cuya cabeza es un televisor. Color.

- Primer plano de la mujer gigante que se quita las gafas de sol para introducirlas en el bolso. Color.

- Plano general del bar en el que aparecen las gafas desde el margen superior del encuadre. Encuadre frontal e inclinación normal. Color.

Segunda intro: Hello again: 01:19 02:16

- Plano de media figura de un personaje femenino. En su pecho descubre la palabra "Hello". Encuadre frontal e inclinación normal. Color.

- Plano de media figura del personaje representado por Andy Warhol. Se encuentra de espaldas a la cámara viendo la televisión, que emite la imagen anteriormente descrita. Encuadre frontal e inclinación normal. Color.

- Campo medio de un bar en el que aparecen cuatro personajes. Uno de ellos es Andy Warhol caracterizado como camarero. Encuadre frontal e inclinación normal. Color.
- Primer plano de uno de los personajes femeninos en cuya lengua aparece la palabra "Hello". Encuadre frontal e inclinación normal. Color.

- Primer plano de uno de los personajes masculinos en cuya lengua aparece la palabra "Again". Encuadre frontal e inclinación normal. Color.

- Plano de media figura del personaje representado por Andy Warhol. Se encuentra de espaldas a la cámara viendo la televisión, que emite la imagen anteriormente descrita. Encuadre frontal e inclinación normal. Color.

- Las imágenes emitidas en la televisión toman el protagonismo a través de un efecto de sobreimpresión. Planos de media figura de un personaje masculino con el torso desnudo mientras se viste con una camiseta en la que aparece la palabra "Hello". Encuadre frontal e inclinación normal. Color.

- Plano medio del cuerpo de una chica con camiseta en la que aparece la palabra "Again", mientras un coche de juguete recorre su cuerpo. Encuadre picado. Color.

- Plano general de dos personajes femeninos semidesnudos sentados entre las letras que forman la palabra "Body". Fondo negro 
y neutro. Encuadre frontal e inclinación normal. Color.

- Este plano se alterna con el plano anterior de la chica con el coche de juguete. Color.

- La imagen de un coche irrumpe en la escena y no permite ver más allá de este. Encuadre frontal e inclinación normal. Efecto de incrustación de dos neumáticos. Color.

- Plano general de una calle en la que aparece un neumático. Inclinación normal. Color.

- Plano detalle de la palabra "Hello" sobre el asfalto, el neumático destruye una letra " $\mathrm{L}$ ". Encuadre picado. Color.

- Plano de la chica con el coche de juguete sobre su cuerpo anteriormente descrito. Color.

- Primeros planos y planos detalle de torsos desnudos, tanto masculinos como femeninos, que son recorridos por coches de juguete. Fondos neutros. Encuadre picado. Color.

- Plano de media figura del personaje representado por Andy Warhol. Se encuentra de espaldas a la cámara viendo la televisión, que emite imágenes en blanco y negro. Encuadre frontal e inclinación normal. Color y blanco y negro.

- Las imágenes emitidas en la televisión toman el protagonismo a través de un efecto de sobreimpresión. Planos americanos, primeros planos y planos detalle de un personaje femenino y otro masculino mientras se besan. Las imágenes alternan el color y el blanco y negro. Dichas imágenes se realizan mediante un travelling a mano, por lo que se caracterizan por la profusión de movimiento. Encuadre frontal.

Estrofa I: 02:17 - 02:54

- Primer plano del cantante sobre un fondo chroma-key con las imágenes anteriormente descritas. En un primer momento el cantante se encuentra de espaldas para después volverse hacia la cámara. Encuadre frontal e inclinación normal. Color.

- El plano se abre hacia un plano medio del cantante. Tras él, continúan las imágenes anteriormente descritas. Encuadre frontal e inclinación normal. Color.

- La imagen del cantante se desvanece y aparecen el resto de componentes del grupo en una composición en mosaico que abarca la totalidad de la escena. Como fondo, las imágenes de la pareja besándose. Los componentes del grupo aparecen en la escena uno tras otro para luego ensombrecerse hasta fundirse con el fondo. Color.

- Plano americano de uno de los componentes del grupo que se 
traslada desde un punto a otro de la escena, mientras la cámara sigue estática. Este personaje invade la escena a través del margen derecho del encuadre, y lo abandona por el margen izquierdo de este. Como fondo de la escena continúan las imágenes de la pareja en otra tonalidad. Encuadre frontal e inclinación normal. Color.

- Primerísimo primer plano del cantante. Encuadre frontal e inclinación normal. Color.

- Travelling tras los componentes del grupo que caminan hacia el interior del bar. Color.

- Campo medio del bar en el que aparece el grupo a un lado de la barra, y Andy Warhol caracterizado como camarero al otro lado. Encuadre en escorzo e inclinación normal. Color.

Estribillo I: 02:55 - 03:13

- Primer plano del cantante. Encuadre frontal e inclinación normal. Color.

- Plano de media figura del resto de componentes del grupo. Encuadre en escorzo e inclinación normal. Color.

- Primer plano del cantante. Encuadre frontal e inclinación normal. Color.

- Plano de media figura de Andy Warhol. Encuadre frontal e inclinación normal. Color.
Estrofa II: 03:14 - 03:26

- Primer plano del cantante. Encuadre frontal e inclinación normal. Color.

- Panorámica oblicua que sigue los movimientos de Andy Warhol mientras realiza las tareas propias de un camarero. Color.

- Primer plano del cantante. Encuadre frontal e inclinación normal. Color.

- Plano de media figura del resto de componentes del grupo. Encuadre en escorzo e inclinación normal. Color.

- Primer plano del cantante. Encuadre frontal e inclinación normal. Color.

- Campo largo del bar en el que aparecen muy diversos personajes así como los componentes del grupo. El recorrido se realiza mediante un movimiento de travelling a mano de la cámara. Los personajes se vuelven hacia la cámara con el paso de esta. Se realizan desde planos más generales hasta primeros planos de algunos de los personajes presentes en la escena. La cámara realiza un movimiento de travelling hacia el fondo de la sala, con intención de mostrar a todos los personajes de la escena. Color.

Estribillo II: 03:27 - 03:48

- La escena sigue desarrollándose en el bar. Movimientos de cá- 
mara con zooms hacia primeros planos de los personajes. Las características de la filmación son las mismas que las descritas en el último plano de la estrofa II.

Estrofa III: 03:49 - 04:06

- La escena continúa en el mismo sentido de los planos anteriores.

- Primeros planos de algunos de los personajes presentes en la escena. Color.

- Plano conjunto de una pareja. La cámara realiza varios movimientos rápidos alrededor de ellos. Aparecen sobreimpresas a estas imágenes las palabras "Fade to blue", cada vez de mayor tamaño, hasta que la palabra "To" abarca la totalidad de la pantalla. Color.

Puente musical: 04:07 - 05: 12

- Plano medio en el que aparece el cantante sobre un fondo neutro de color rojo. Aparece por el margen izquierdo del encuadre un neumático, para desaparecer por el margen opuesto. Encuadre frontal e inclinación normal. Color.

- Fondo neutro negro. Efecto de incrustación de neumáticos y las palabras "Hello" y "Again", esta última aparece invertida. Color.

- Plano de media figura de una chica con un postre de gelatina que forma la palabra "Hello".
La cámara realiza un travelling hacia atrás a gran velocidad. Encuadre frontal e inclinación normal. Color.

- Campo medio del cantante junto a otros dos personajes femeninos mientras ingiere el postre de gelatina a cámara rápida. La inclinación del plano es superior al resto de planos para integrar el postre con la palabra "Hello". Encuadre levemente picado. Color.

- Plano de media figura del perfil del cantante situado en una oficina de teleoperadores. Inclinación normal. Color.

- Travelling a gran velocidad alrededor de dos personajes mientras se están besando. Inserto de imágenes de neumáticos. Encuadre picado. Blanco y negro.

- Plano general de una ciudad. Palabras sobreimpresas: "Electric", "Loose", "Eclectic" y "Eclektic". Color.

- Fondo neutro negro. Palabras sobreimpresas "Look". Color.

- Primer plano de un personaje femenino. Encuadre frontal e inclinación normal. Color.

- Fondo neutro negro. Palabras sobreimpresas "Wait". Color.

- Plano americano del mismo personaje femenino anteriormente descrito, con camiseta "Hello". 
Encuadre frontal e inclinación normal. Color.

Estribillo III: 05:13 - 06:16

- Travelling a mano alrededor de la chica que lleva las letras "Hello" en su pecho. Color.

- Las imágenes de los personajes del bar realizadas mediante un travelling a mano sirven como fondo para las palabras sobreimpresas de la letra de la canción, que funcionan a modo de subtítulos de esta. Color.

- Plano medio en el que aparece la palabra "Body" sobre un fondo celeste. El cantante aparece por el margen izquierdo del encuadre y se sienta sobre las letras. Cambio del color del fondo. Las letras de la palabra "Body" son arrojadas contra el cantante mientras permanece inmóvil. Encuadre frontal e inclinación normal. Color.

- Fondo neutro rojo en el que aparece la letra de la canción de forma sobreimpresa. Color.

- Primer plano de un torso femenino desnudo que recorre un coche de juguete. Encuadre picado. Color.

\section{- Movilidad}

La mayor parte de los planos de este video musical se definen por el estatismo de la cámara, sin embargo, también se encuentran en él movimientos singulares, siendo el más característico el plano-secuencia que inicia el videoclip y mediante el que se muestra una ciudad irreal en la que los iconos de los Estados Unidos pasan a convertirse en iconos de la banda que interpreta la canción. Casetti y Di Chio (1991: 108) definen el concepto del planosecuencia como una toma en continuidad, es decir, una sucesión de elementos que son presentados ante el espectador sin ningún tipo de corte ni transición a través de un encuadre único.

Además del plano-secuencia inicial, se describen en este video musical otros movimientos de cámara, tanto reales como aparentes, dotando al espacio encuadrado de gran dinamismo y velocidad. Entre los movimientos reales se describen panorámicas horizontales que siguen a algún objeto, como en el caso del neumático que rueda por una calle, y panorámicas oblicuas, sirviendo de ejemplo la realizada para seguir los movimientos de Warhol caracterizado como barman mientras efectúa las labores propias de dicho oficio. Son abundantes los travellings a mano, que subrayan la sensación de velocidad y fluidez, que aparecen en varias escenas: en el remake del filme warholiano Kiss (1963), escena en la que aparecen dos jóvenes besándose siendo registrados a gran velocidad; en el interior del local para mostrar al espectador la to- 
talidad de personajes que pueblan la escena; alrededor de Diane Brill en la escena final mientras ella se encuentra en la puerta del local. En cuanto a los movimientos aparentes, se realizan varios zooms tanto hacia adelante como hacia atrás. Los zooms se utilizan generalmente para mostrar primeros planos de los personajes o bien para ampliar el plano, permitiendo que el espectador perciba una mayor información del espacio. Otra característica singular en cuanto a la movilidad, y en relación con el montaje, es la técnica de stop-motion utilizada en las escenas en las que pequeños coches de juguete recorren los torsos desnudos de algunos personajes. Esta técnica, empleada en animación, consiste en rodar cuadro a cuadro objetos inmóviles para que una vez montados los planos correlativamente cobren movimiento.

\section{- Iconografía}

Los elementos iconográficos de este video musical hacen referencia a dos aspectos: por una parte, aluden al mundo y a las obras de Andy Warhol, y por otra, al grupo intérprete de la canción. El mundo del artista queda reflejado en los personajes que componen la escena del club, quienes se asemejan o forman parte de la Factory o de la revista Interview, como Diane Brill, John Sex y Benjamin Liu, que participan en el video musical. Igualmente se hace referencia a la obra tanto pictórica y audiovisual de Andy Warhol con la presencia de los zapatos de tacón, aludiendo a sus primeras obras como Shoes, shoes, shoes (1955). En cuanto a las obras cinematográficas warholianas, se hace mención en este videoclip a los filmes The Chelsea girls (1966), al aparecer el cantante frente a un hotel con el nombre "Charley Hotel", Kiss (1963), mediante inserción de imágenes en blanco y negro de una pareja besándose, y los Screen Tests (1964-1966), ya que aparecen numerosos personajes sobre un fondo neutro del mismo modo que en dichas piezas.

Asimismo, tiene su presencia la estética del arte Pop y la estética New Wave en el uso de colores planos y vivos, y en la disposición de los elementos del escenario inicial, compuesto por objetos del tocador femenino como polveras, barras de labios, peine y botes de laca y perfume. Se observan características del Pop Art en el uso de iconos de los Estados Unidos que componen el plano-secuencia inicial, en el que se identifican elementos como la Estatua de la Libertad, las letras que forman la palabra Hollywood, el monte Rushmore o el puente de Brooklyn, entre otros. Estos elementos se encuentran citados de forma indirecta, a través de su conversión en referentes de la banda The Cars, para los que se adaptan 
dichos iconos norteamericanos, por ejemplo la palabra Hollywood de gran tamaño situada en la cima de Cahuenga Peak se transforma en las palabras Heartbeat City, en una doble alusión al grupo The Cars, y a Hollywood como representación de los Estados Unidos.

El otro conjunto de códigos iconográficos se compone por los elementos que representan a los miembros del grupo, con juegos visuales sobre el nombre de este, The Cars, ya que aparecen numerosas referencias a los coches o a partes de estos. Ejemplos de ello se encuentran en los coches-zapato que circulan por el escenario ficticio de la escena inicial, en los coches de juguete que se desplazan por los torsos desnudos de los jóvenes, neumáticos y tapacubos, e incluso la imagen de un coche que impacta con las chicas junto a las letras de la palabra "Body", incrustado mediante la técnica del chroma-key.

Al margen de estos grupos de elementos iconográficos, se han encontrado en este video musical múltiples referencias a la televisión, objeto que aparece de forma material, en la cabeza del barman de la escena de inicio y en las gafas de sol y en la presentación de Andy Warhol como camarero mientras está viendo la televisión. Pero dicho aparato también es aludido a través de interferencias propias de este, sirviendo como ejemplo, las letras iniciales que componen el nombre del grupo, y cuyo interior está formando por la señal mal ajustada de un televisor, efecto que se produce cuando las gafas-TV se acercan hacia la pantalla simulando este mismo efecto. Esta peculiaridad entronca con las características del cine estructuralista, entre las que se encontraba la grabación de imágenes directamente de una pantalla de televisión o de una proyección.

\section{Códigos gráficos}

Entre los códigos gráficos no diegéticos aparecen en primer lugar las palabras "The Cars" a modo de título al inicio del videoclip. Estas letras son de gran tamaño y se presentan en mayúsculas y de gran grosor con relleno de efecto de un televisor mal ajustado. Dichas palabras aparecen por el margen derecho y van desapareciendo por el margen izquierdo del encuadre dejando paso a las siguientes letras, hasta completar el nombre del grupo. A continuación, se insertan dentro del plano-secuencia, a través de incrustaciones otros grafismos no diegéticos como las palabras "Heartbeat City" en color blanco y mayúsculas, en referencia a las letras de Hollywood ubicadas en la cima del Cahuenga Peak. También aparecen las palabras "Bulletin Products", "Directory Boards", "Air Acondicioned", "Charley Hotel" "For singles and couples" en 
distintas grafías, colores y tamaños. Estas palabras funcionan como textos dentro de la ficción representada, pero no se encuentran en la realidad filmada, tan solo la simulan, ya que estos grafismos se insertan posteriormente durante la fase de posproducción. Al final de la tercera estrofa, aparecen sobreimpresas en la imagen las palabras "Fade to blue" a modo de subtítulos de la letra de la canción. Estas palabras emergen del centro de la imagen para crecer en tamaño hasta desaparecer por los márgenes del encuadre. La palabra "To" se mantiene en la pantalla en el siguiente plano, y se difumina poco a poco hasta fundirse con el fondo. También funcionando como subtítulos aparecen las palabras "Hello again" ("again" aparece invertida), "electric", "loose", "eclectic", "eclektic", "look", "wait", "your might have forgot", "you made your friends", "you gave the best", "you just want to fly", "you gave your body" $\mathrm{y}$ "the journey ends", que forman parte de la letra de la canción y ejercen la función dentro del video musical de subtítulos de esta. Se caracterizan por los colores vivos.

Igualmente, se describen códigos gráficos diegéticos, siendo las palabras "Hello" y "Again" las que aparecen repetidas mayoritariamente en diferentes soportes como sobre partes del cuerpo como la lengua y el pecho, o impresas en camisetas, pendientes y postre de gelatina. La palabra "Hello" es la más frecuente, y llega a aparecer incluso sobre la carretera. Otros grafis- mos son los contenidos en los carteles ubicados en las paredes del local que hacen referencias a actuaciones y conciertos. Asimismo, aparece la palabra "Body", con cuyas letras se llega a interactuar.

\section{Códigos sonoros}

Los códigos sonoros hacen alusión a los elementos relacionados con la voz, la música y los sonidos naturales. En "Hello again" predominan las partes instrumentales, es decir, la música sobre la voz. También se caracteriza por la ausencia de sonidos procedentes del ambiente o la naturaleza. La banda sonora está compuesta íntegramente por la canción como base, a la que no se añade ningún elemento de sonido. La música es no diegética, ya que la fuente de sonido no se encuentra dentro de la realidad presentada en el video musical, tratándose por tanto de sonidos over.

Aparece de nuevo en este vídeo musical la intención de sincronizar la banda sonora y la banda icónica, mediante el playback del cantante que interpreta la canción mientras interpela a la cámara y al espectador. Se produce un simulacro de fidelidad con la fuente de sonido, convirtiendo lo no diegético en apariencia de diegético.

La lengua del cantante es el inglés, idioma en el que se interpreta la canción. Como se ha comentado anteriormente, la música tiene mayor presencia en este vídeo, ya que se eligió para él la versión extendida de "Hello 
again", a la que además se añadió un sampler de otro single del mismo LP, Heartbeat city. La parte instrumental de la canción tiene mayor peso en ella que la voz del cantante, no obstante, la letra de la canción se subraya mediante la incrustación de esta a modo de subtítulos.

\section{Códigos sintácticos o del montaje}

El montaje de los planos y de las distintas escenas se caracteriza por la velocidad, esto se traduce en los cambios rápidos y frecuentes de un plano a otro mediante cortes o con encadenado de imágenes sobreimpresas sobre las siguientes.

Dicha característica se une al montaje asociativo realizado en varios momentos de este video musical, sirviendo de ejemplo la escena inicial en la que mediante el montaje de planos correlativos se sugiere que el bar irreal, compuesto por objetos de tocador y cuyo barman posee como cabeza un televisor, se localiza en el interior del bolso del personaje femenino que aparece en la escena anterior. Este personaje introduce tanto al cantante como sus gafas de sol, que posteriormente aparecen por el margen superior del encuadre.

Resulta peculiar el desarrollo en Hello again de dos acciones paralelas. Por una parte se presentan acciones realizadas en el club en el que Andy Warhol actúa como camarero, mientras que por otra parte se desarrollan actividades paralelas que son conecta- das a través de la televisión localizada en el bar, y que funcionan como elipsis de la acción principal, es decir, la ejecutada por los miembros de la banda The Cars con carácter performativo. Dicho paralelismo se subraya con el cambio del color al blanco y negro, lo que denota dos unidades espaciotemporales diferentes.

El cambio de plano a plano se produce de forma muy rápida, generalmente mediante cortes simples, sin efectos de transición entre ellos. Esta característica incide de nuevo en el interés por crear un video musical dinámico y fluido, en el que los mismos planos se alternan entre ellos a gran velocidad, manteniendo al espectador concentrado en lo que está viendo.

\section{Análisis de la representación}

\section{Puesta en escena}

- Decorados y escenarios: Las localizaciones principales en las que se desarrolla este videoclip son dos clubes, el primero de ellos presentado al inicio y caracterizado por elementos y colores irreales que lo dotan de un aspecto artificial y ficticio; y el segundo club, más realista, en el que tiene lugar la acción principal, cuando la banda llega al bar y se reúne allí con el resto de personajes. El primero se muestra como un decorado creado específicamente para su uso en el video 
musical, mientras que el segundo se presenta como un escenario real. El resto de acciones se ubican en diferentes escenarios y decorados como en un estudio interior, en el que no se muestran objetos con los que los personajes puedan interactuar y cuyo fondo está compuesto por un fondo neutro que sirve en ocasiones para insertar las imágenes mediante la técnica del chroma-key. Otras actividades se desarrollan en una calle urbana y en una falsa oficina de teleoperadores.

- Vestuario y maquillaje: En relación con el vestuario de los personajes, la elección de este para los miembros de la banda The Cars refuerza su identidad individual, respetando su propia personalidad. De este modo, el grupo aparece en el videoclip con distintos vestuarios pero todos ellos siguen una misma línea estilística, afín a la moda de los años ochenta, en la que predominan las chaquetas con hombreras y de colores y estampados 1lamativos, combinadas con camisetas y camisas. El cantante se caracteriza por el uso de corbatas y gafas de sol, en cuyo vestuario destaca el predominio del color negro. Andy Warhol aparece caracterizado como barman con traje de chaqueta negro y camisa blanca. También lleva una pajarita brillante de color rojo y negro con lentejuelas, complemento con el que solía vestir el propio Warhol y que incluso llegó a ser motivo para alguna de sus obras pictóricas como Bow ties (1960). El resto de personajes aparece caracterizado de forma afín a su rol dentro del video musical, destacando el uso de camisetas en las que aparecen las palabras "Hello" y "Again" que llevan gran parte de los extras. Benjamin Liu aparece travestido en el video mientras que John Sex se representa a sí mismo mediante su indumentaria.

- Iluminación y color: La iluminación es artificial ya que las acciones se desarrollan en interiores, aun así las escasas escenas en exteriores, como en la que aparece un neumático que cruza la calle, se caracterizan por el uso de la luz natural. Esta luz artificial es predominantemente de color blanco e ilumina la escena de forma total, no iluminando ningún objeto o personaje de forma selectiva ni significativa. Se usan focos de colores para las escenas ubicadas en el interior del club, lo que acentúa el ambiente festivo y de actuación representado.

En lo referente al color, destacan los colores vivos y planos, así como los pastel, lo que recuerda a la estética del arte pop y de la tendencia New Wave. Esta característica se refleja sobre todo en el bar que aparece al inicio del video musical, en el que los objetos presentan este tipo de colores planos pero muy vivos y llamativos, que dan a la escena un mayor efecto de arti- 
ficialidad. Entre estos colores planos destacan el rosa pálido, el turquesa, el violeta, el verde limón, el azul, el fucsia, el rojo, el amarillo y el negro; ninguno de ellos presenta ningún tipo de escala cromática ni gradación tonal.

- Expresión y movimiento de las figuras: Mediante los movimientos de la cámara, tales como travellings y panorámicas, y el montaje a gran velocidad y con cortes de plano a planos muy rápidos, se produce en Hello again un efecto de velocidad y dinamismo que se ve reforzado a través de la profusión de los movimientos profílmicos, es decir, en el interior de la escena filmada. Tanto los personajes como otros elementos, como los coches de juguete o los neumáticos, realizan gran variedad de movimientos que aumentan dicha sensación. La combinación de estos aspectos (movilidad, montaje y movimiento profílmico) crean un espacio caracterizado por la agitación, el cambio y la fluidez. La expresión y el movimiento de los personajes que construyen las distintas escenas guardan relación con el carácter performativo de este video musical; por ello, los movimientos de los personajes se corresponden con los roles desempeñados por ellos. Dichos roles son reseñados en el apartado dedicado a los existentes en el análisis de la narración.

\section{Espacio videográfico}

El espacio se define principalmente por ser estático móvil, es decir, la cámara permanece fija mientras que en el interior de la escena se producen gran variedad de movimientos, incluso algunos que sobrepasan los márgenes del encuadre, siendo habitual las invasiones de objetos y personajes desde los márgenes del encuadre. En Hello again se observa este fenómeno, por ejemplo, cuando el cantante es arrojado por un personaje femenino al interior de su bolso. En el plano siguiente, el cantante aparece por el margen superior como si cayera desde la mano de la mujer. Del mismo modo aparecen en escena las gafas de sol. Este hecho se repite cuando los miembros de la banda aparecen por el margen derecho del encuadre para desaparecer por el margen opuesto, mientras la cámara permanece fija. Este tipo de espacio es definido por Casetti y Di Chio (1991: 144) como un espacio contenedor, vivo en su interior pero limitado por los inevitables márgenes; móvil y mudable porque hospeda figuras y formas móviles y mudables, pero no porque esté dotado de dinamismo y fluidez.

El movimiento de la cámara también descrito en algunos momentos de este videoclip construye otro tipo de espacio, en este caso dinámico descriptivo, en el que la cámara acompaña y sigue los movimientos de los personajes dispuestos en la escena, ofreciendo distintos puntos de vis- 
ta y contribuyendo a la sensación de movimiento, dinamismo y velocidad. Este tipo de espacio se traduce en escenarios profundos y de tipo realista, en el que los personajes se desplazan en su totalidad. No obstante, los espacios creados mediante la técnica del chroma-key en la fase de posproducción del video musical se muestran planos, pues resulta imposible que los personajes interactúen con los elementos presentes en ellos o que puedan moverse por ellos.

En conclusión, se presentan en Hello again dos tipos de espacios muy contrastados -estático móvil y dinámico descriptivo- pero equilibrados, dependiendo del uso que se realice de los movimientos -o la ausencia de ellos- de la cámara.

\section{Tiempo videográfico}

El tiempo videográfico mantiene una estrecha relación con la narración y los códigos del montaje, ya que la primera marca la duración de las acciones y de la trama, y los segundos determinan la presencia de elipsis, las pausas y la frecuencia de los planos. Todos estos aspectos se encuentran vinculados con el tiempo.

Este video musical se caracteriza por la ausencia de una trama, aunque sí se realizan varias acciones paralelas y que, por lo tanto, responden a esquemas temporales simultáneos. La primera acción es la relacionada con la llegada de los miembros del grupo al bar donde los espera Andy Warhol como barman y el resto de personajes. Esta acción se presenta de forma lineal, alternándose con la segunda actividad mediante elipsis. La segunda acción tiene lugar en un escenario diferente y por tanto en un tiempo diferente. Es la escena de los dos personajes que se besan citando la película Kiss de Andy Warhol. Esta secuencia se presenta de forma fragmentada, e interrumpe el resto de escenas del video musical.

El tiempo en Hello again se presenta de forma fragmentaria y confusa, ya que este video posee como característica principal la velocidad, el movimiento y el dinamismo, y los planos y escenas se intercalan unos entre otros creando pausas y elipsis de forma continua, y presentando acciones que dan sensación de simultaneidad.

\section{Análisis de la narración}

\section{Existentes}

En relación con los personajes, estos pueden agruparse en cuatro tipos, diferenciados entre sí por su nivel de importancia dentro del video musical y por su rol en este. El primer grupo lo componen los miembros de la banda intérprete de la canción, The Cars, predominando sobre ellos el cantante. Ellos actúan interpretándose a sí mismos, pero también como personajes dentro de la escena. El segundo tipo solo se compone por Andy Warhol, quien actúa como barman dentro de la 
acción del bar. La tercera y la cuarta tipologías están formadas por el resto de personajes que pueblan las escenas, distinguiendo entre los personajes afines a Andy Warhol y procedentes del mundo de la Factory como Benjamin Liu, John Sex, Diane Brill y Gina Gershon, y el resto de personajes que figuran como extras.

En cuanto a los ambientes, se ha tratado de escenificar el ambiente ecléctico de la Factory, a través de sus personajes, las luces de colores y la naturaleza performativa de este video musical, cuyo principal interés es la actuación y el despliegue técnico por encima de la narración. Se recrea un ambiente festivo, realista y contemporáneo, mediante el que se contextualiza a los personajes cuyas actitudes se presentan como festivas y despreocupadas.

\section{Acontecimientos}

Hello again es un video musical fundamentalmente performativo, en el que predomina el despliegue técnico y la intención estética frente el interés por contar una historia o mostrar una acción. Las acciones se encuentran subordinadas a las actividades desempeñadas por los miembros de la banda y por el resto de personajes, pero dichas acciones no forman parte de una estructura narrativa subyacente, sino que son solo una secuencia de actos.

Se desarrollan acciones como la llegada del grupo al club, el barman sirviendo a los clientes, el cantante interpretando la canción mientras mira hacia la cámara, otros personajes besándose, algunos otros realizando su actuación como John Sex, entre otras acciones que forman parte del carácter performativo del video musical.

No se describen sucesos en relación con ningún tipo de hecho colectivo o procedente de la naturaleza. Este tipo de acontecimientos suelen caracterizarse por su ausencia en lo referente a los videos musicales, aunque sí suelen ser frecuentes en las obras cinematográficas.

\section{Interpretación}

The Cars era una banda estadounidense de New Wave, corriente musical surgida en los años setenta. La banda se formó en 1976 liderada por Ric Ocasek y compuesta por Benjamin Orr, Greg Hawkes, Elliot Easton y David Robinson. En 1977 consiguieron un contrato discográfico con Elektra Records y lanzaron su primer disco al año siguiente. Su disco más exitoso fue Heartbeat city de 1984, en el que se encuentra el single Hello again. Un año después, los miembros de The Cars acordaron una pausa para realizar proyectos en solitario -su líder, Ric Ocasek, ya había grabado en solitario un LP en 1983-. La banda se separó definitivamente en 1988, pero en el 2010 anunciaron el lanzamiento de un nuevo álbum de estudio, sin la presencia de Benjamin Orr, quien falleció a causa de un cáncer en el año 2000. 
El video musical Hello again se inicia con una intro musical que tiene como base musical el single que da título al disco, Heartbeat city. En ella se dan algunos rasgos estéticos de la tendencia New Wave, como el uso de colores planos en tonalidades pastel y la profusión de colores, que también mantienen relación con el Pop Art. Se describe en esta intro un mundo artificial en el que predominan los referentes a iconos norteamericanos que forman parte del universo colectivo de los estadounidenses, así como referencias a la mujer y lo femenino.

Este videoclip supone un gran despliegue de efectos y técnicas, cuya acción se desarrolla en el Be-Bop Café, local frecuentado por Andy Warhol y su séquito, y en el que se recrea una escena festiva que recuerda a los espectáculos multimedia que se producían en la Factory en los años sesenta, como The Exploding Plastic Inevitable y Up-Tight. En ellos tenían lugar actuaciones en directo de The Velvet Underground mientras se proyectaban imágenes de las películas de Andy Warhol, con luces estroboscópicas de colores. Al mismo tiempo, Gerard Malanga y otros personajes frecuentes en la Factory realizaban bailes sobre el escenario. Callie Angell (2000: 58) destaca, de este tipo de espectáculos multimedias, el uso de las producciones cinematográficas warholianas a modo de proyecciones, combinadas con las actuaciones musicales y las luces de colores, por lo que sus pelí- culas se mezclaban con la música, el arte y el espectáculo en una suerte de happening que servía al mismo tiempo de vehículo promocional para las películas de Warhol. También David Alcalde (2000: 59) incide en las características de estos espectáculos lumínicos de los que subraya su naturaleza sinestésica, gracias a la mezcla de música, luces y proyecciones, en las que el asistente-espectador se encontraba inmerso en una experiencia global e integral que excitaba y estimulaba sus sentidos por diversos flancos.

Hello again refleja esta atmósfera de performance, música, actuaciones, luces de colores y pompas de jabón en las escenas desarrolladas en el Be-Bop Café en el que vemos a distintos personajes bailando sobre las mesas como a Benjamin Liu travestido, un mimo, y John Sex realizando una performance junto a su serpiente. La cámara rápida trata de recrear el ambiente de locura que caracterizaba los espectáculos multimedia desarrollados en la Factory warholiana. Music Television (MTV) censuró esta versión del video musical por su contenido sexual al incluir numerosos desnudos femeninos. Por ello, la productora se vio obligada a realizar una nueva versión de menor duración y en la que se eliminaron, además de los desnudos, otras partes como la intro musical, reduciendo el video musical casi a la mitad del videoclip original. 


\section{Conclusión}

El video musical carece en la actualidad de un método propio que se adecúe a sus singularidades y características como formato experimental y posmoderno.

Este artículo pretendía describir una propuesta analítica basada en estudios de campos afines al videoclip como son el cine y la publicidad.

A partir de ellos se ha diseñado una plantilla de estudio dispuesta en tres etapas principales, y subdivididas en distintas fases cada una de ellas. Dicho método ha sido aplicado al video musical Hello again como ejemplo práctico, revelando las posibles deficiencias y las potencialidades de este.

El análisis crítico-estilístico tiene como objetivo establecerse como una herramienta de estudio y análisis del video musical en el ámbito de la educación, aplicable a cualquier tipo de videoclip, narrativo o no narrativo, o con las singularidades que entraña cada estilo musical como pop, rock, heavy, jazz, metal, reggae, punk, folk, country, etcétera.

La objetividad, la eficacia y la rigurosidad son los valores de los que parte esta propuesta metodológica, que pretende dar solución a una carencia en el análisis audiovisual y servir como herramienta educativa y cultural.

\section{Bibliografía}

Aguaded, José Ignacio y María Amor Pérez (1995). "La imagen de la imagen". Comunicar 4, 64-68.

Angell, Callie (2000). "Andy Warhol, cineasta", en Andy Warhol: Cine, vídeo y TV. Barcelona: Fundació Antoni Tápies/Diputación de Granada/ Fundación Pablo Ruíz PicassoMuseo Casa Natal/Ayuntamiento de Málaga.

Alcalde, José Ángel (2000). “El cine de Andy Warhol". Lápiz 165, 55-62.

Aumont, Jacques y Michel Marie (1990). Análisis del film. Barcelona: Paidós.

Bordwell, David y Kristin Thompson (1995). El arte cinematográfico. Barcelona: Paidós.

Carmona, Ramón (2000). Cómo se comenta un texto fílmico. Madrid: Cátedra.

Casetti, Francesco y Federico Di Снiо (1991). Cómo analizar un film. Barcelona: Paidós.

Correa, Ramón Ignacio; Guzmán, María Dolores y José Ignacio Aguaded (2000). La mujer invisible. Una lectura de los mensajes publicitarios. Huelva: Grupo Comunicar.

González Requena, Jesús y Amaya Ortiz de Zárate (1995). El espot publicitario. La metamorfosis del deseo. Madrid: Cátedra. 
Martí Perelló, Sara y Sergio Warhol, Andy y Pat Hackett (1990). Vallhonrat Bodas (2000). "Lo ver- Diarios. Barcelona: Anagrama.

bal y lo no verbal en el mensaje publicitario televisivo". Contextos, XVII-XVIII/33-36, 223-241.

Zunzunegui, Santos (1989). Pensar la imagen. Madrid: Cátedra.

Pérez Gauli, Juan Carlos (2000). El cuerpo en venta. Relación entre arte y publicidad. Madrid: Cátedra. 